\title{
The Effects of Internal Heat Generation or Absorption on Mixed Convection in a Lid-Driven Rectangular Cavity using Finite Volume Method
}

\author{
Norhaliza Abu Bakar ${ }^{1}$, Rozaini Roslan 2,3, ${ }^{*}$, Mohd Kamalrulzaman Md Akhir ${ }^{3,4}$
}

1 Department of Science and Mathematics, Centre of Diploma Studies, Universiti Tun Hussein Onn Malaysia, 84600 Pagoh, Johor, Malaysia

2 Centre for Research in Computational Mathematics, Faculty of Sciences and Applied Technology, Universiti Tun Hussein Onn Malaysia, 84600 Pagoh, Johor, Malaysia

3 ANNA Systems, LLC, INN 5010049861, KPP 501001001, OGRN 1155010000694, 141981, Moscow Region, Dubna, 9 Maya Street, Building 7B, Building 2, Office 10.141707, Moscow, Dolgoprudnenskoe Highway, 3, Fiztekhpark, Russia

4 Institute of Engineering Mathematics, Faculty of Applied and Human Sciences, Universiti Malaysia Perlis, Pauh Putra Campus, 02600 Arau, Perlis, Malaysia

\section{ARTICLE INFO}

\section{Article history:}

Received 21 October 2020

Received in revised form 22 December 2020

Accepted 22 December 2020

Available online 30 December 2020

\section{Keywords:}

Finite volume method; heat absorption heat generation; horizontal cavity; liddriven

\section{ABSTRACT}

Mixed convection heat transfer in cavities is a significant phenomenon in numerous engineering fields, such as nuclear reactors, solar energy storage, and heat exchangers. Despite acknowledging that a square is a basic shape found in these systems, not all the figures are geometrical. Less attention was given to the rectangle cavity even though it could be found in these systems. Various internal reactions could occur inside the systems, especially in geothermal heat exchangers. Therefore, this research aims to analyze the effect of internal heat generation or absorption in a two-dimensional (2D) horizontal cavity to the fluid flow and heat transfer process numerically. The vertical walls are well insulated. Meanwhile, the top and bottom walls are kept at $T_{h}$ and $T_{c}$, respectively, where $T_{h}>T_{c}$. The top wall moves at a constant speed from left to right. The finite volume method (FEM) and SIMPLE algorithm are employed to discretize the governing equations. Next, the algebraic equations are solved iteratively using the tri-diagonal matrix algorithm (TDMA). The influences of heat generation or absorption parameters are investigated in terms of the flow, heat transfer, and Nusselt number. The numerical results are plotted in the form of streamlines and isotherms. It is found that the presence of heat generation or absorption has a significant effect on the fluid flow and heat transfer process in the horizontal cavity. Overall, for internal heat generation, the heat transfer rate decreases, while the opposite pattern can be observed for the case of internal heat absorption. However, for $\mathrm{Ri}=10.0$, as the heat generation's value increases from 2 to 4 , the heat transfer rate is the same.

Copyright @ 2020 PENERBIT AKADEMIA BARU - All rights reserved

\footnotetext{
* Corresponding author.

E-mail address: rozaini@uthm.edu.my (Rozaini Roslan)
} 


\section{Introduction}

Combining the equal effect of shear stress and buoyancy forces in a cavity is called mixed convection. Mixed convection happens in various applications of engineering fields, such as ventilation of rooms, cooling of electronics, paper production, wire drawing, glass fiber production, nuclear reactors, and the boundary layer control in the field of aerodynamics [1-5]. Numerous researchers studied convective flow with distinct configurations and boundary conditions [6-23]. Begum et al., [24] studied the thermal and flow field of the mixed convection flow in a rectangular porous cavity filled with nanofluid subjected to the impact of an inclined uniform magnetic field with sinusoidal heating on the vertical walls. It was found that Hartmann's number and the magnetic field orientation harm convection, leading to the reduction of heat transfer rate. Another work of mixed convective heat flow was investigated by Mehmood [25] on two entrapped trapezoidal cavities filled with ferrofluid. The cavities were placed under the influence of the magnetic field. The concentration of solid ferro particles, Darcy, Grashof, and Hartman numbers has a significant effect on energy and fluid flow patterns from the analysis.

Mixed convection in a square cavity filled with nanofluid is examined numerically by Muthtamilselvan and Doh [26]. The study considered the effect of internal heat generation on fluid flow and heat transfer. It was found that the fluid flow and heat transfer in the cavity was strongly affected by the Richardson number. Moreover, Sivasankaran et al., [27] investigated mixed convection flow and heat transfer in a square cavity with corner heating and internal heat generation or absorption. It was observed that at a forced convection-dominated regime, the heat transfer rate is improved when the heater's vertical length is higher than the horizontal length.

In comparison, Rajarathinam and Nithyadevi [28] explored unsteady laminar convection in a porous cavity filled with nanofluid in the presence of internal heat generation. The system has been modeled by Darcy-Brinkman-Forchheimer equations and was solved using the SIMPLE algorithm. The obtained results revealed that in the presence of strong internal heat generation, nanofluid utilization is insignificant. A problem of mixed convection in a double-sided lid-driven cavity with the presence of volumetric heat generation or absorption was solved by Hussain et al., [29]. The results indicate that the highest heat transfer is when the maximum value of heat absorption is applied. The mixed convection problem with heat generation in different configurations was done by numerous researchers [30-33]. It is observed that heat generation and absorption play a significant effect on the fluid flow and heat transfer in a cavity.

From the above literature review, mixed convection in square geometry and internal heat generation has captivated researchers' interest, and its wide application has enclosed the wide variety in engineering fields. Nevertheless, rectangular cavities were paid less attention by researchers, especially a shallow cavity, even though these are common shapes in plenty of industrial applications, such as gas turbines and heat exchangers. Moreover, it is observed that the study on the effect of internal heat generation and absorption is vital in predicting the heat transfer and flow field. Although many studies have been reported, numerical simulation on mixed convection of Newtonian fluid (water) in a rectangle cavity, including internal heat generation or absorption, has not been analyzed to the authors' best knowledge.

Therefore, this paper illustrates the effect of internal heat generation or absorption on the flow and heat transfer from a rectangular cavity with an aspect ratio (height/width) of five. Then, these effects were analyzed physically. The impact of internal heat generation or absorption, $-6 \leq \Delta \leq 6$, which have Prandtl number $\operatorname{Pr}=7.0$, is presented in streamlines, isotherms, and Nusselt number. 


\section{Methodology}

\subsection{Mathematical Formulation}

Figure 1 shows the system's schematic diagram under consideration with a water-filled rectangular lid-driven cavity of width $L$ and height $H$. The aspect ratio of the cavity is defined as $A R=$ $\frac{L}{H}$. The water used is considered Newtonian fluid, incompressible, and the flow is assumed to be steady, laminar, while the Boussinesq model approximates the density variation. The upper wall moves from left to right at a uniform speed $U_{x}$ and is kept at a constant hot temperature $T_{h}$, while the bottom wall is kept at a constant cold temperature, $T_{c}$. The vertical walls are assumed to be adiabatic, and the effects of internal heat generation or absorption range from -6 to 6 for Richardson number, $R i=0.1,1.0$ and 10 are analyzed.

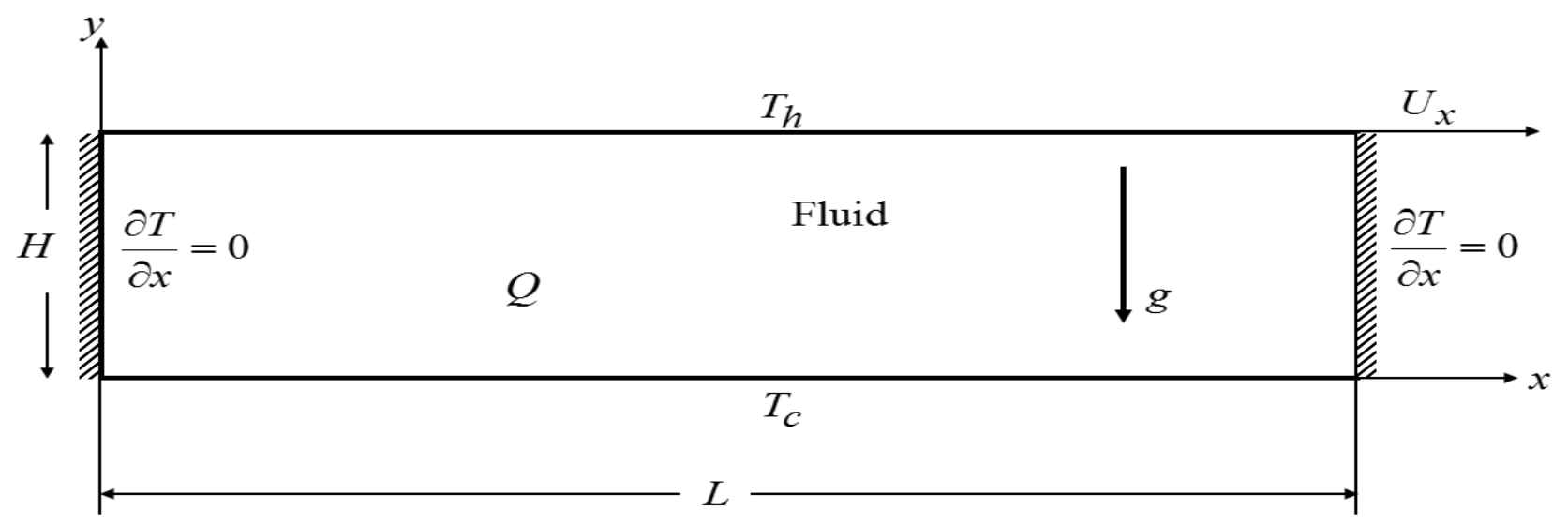

Fig. 1. The geometry of the cavity and boundary conditions

Based on the assumptions, continuity, momentum, and energy in two-dimensional dimensionless equations can be written as follows

$$
\begin{aligned}
& \frac{\partial U}{\partial X}+\frac{\partial V}{\partial Y}=0 \\
& U \frac{\partial U}{\partial X}+V \frac{\partial U}{\partial Y}=-\frac{\partial P}{\partial X}+\frac{1}{\operatorname{Re}}\left(\frac{\partial^{2} U}{\partial X^{2}}+\frac{\partial^{2} U}{\partial Y^{2}}\right), \\
& U \frac{\partial V}{\partial X}+V \frac{\partial V}{\partial Y}=-\frac{\partial P}{\partial Y}+\frac{1}{\operatorname{Re}}\left(\frac{\partial^{2} V}{\partial X^{2}}+\frac{\partial^{2} V}{\partial Y^{2}}\right)+\frac{G r}{\operatorname{Re}^{2}} \theta, \\
& U \frac{\partial \theta}{\partial X}+V \frac{\partial \theta}{\partial Y}=\frac{1}{\operatorname{RePr}}\left(\frac{\partial^{2} \theta}{\partial X^{2}}+\frac{\partial^{2} \theta}{\partial Y^{2}}\right)+\frac{\Delta}{\operatorname{RePr}} \theta
\end{aligned}
$$

subject to boundary conditions

top wall

$$
\begin{aligned}
& : U=1, \quad V=0, \quad \theta=1, \\
& : U=V=0, \quad \theta=0,
\end{aligned}
$$$$
\text { bottom wall }
$$ 
left and right walls $: U=V=0, \frac{\partial \theta}{\partial X}=0$.

In Eqs. (1) - (5), $U$ and $V$ are the $X$ and $Y$ component velocity respectively, $\theta$ is the temperature, $\mathrm{Re}$ is the Reynolds number, $\mathrm{Pr}$ is the Prandtl number, $\mathrm{Gr}$ is the Grashof number, $P$ is the pressure, $\Delta$ is the internal heat generation or absorption coefficient, and $\mathrm{Ri}=\frac{\mathrm{Gr}}{\mathrm{Re}^{2}}$ is the Richardson number. In the present analysis, the dimensionless variables used are

$$
X=\frac{x}{H}, Y=\frac{y}{H}, U=\frac{u}{U_{x}}, V=\frac{v}{U_{x}}, \theta=\frac{T-T_{c}}{T_{h}-T_{c}},
$$

$$
\mathrm{Gr}=\frac{g \beta\left(T_{h}-T_{c}\right) H^{3}}{v^{2}}, \operatorname{Pr}=\frac{v}{\alpha}, \operatorname{Re}=\frac{U_{x} H}{v}, \Delta=\frac{Q H^{2}}{\alpha \rho C_{p}},
$$

where $u$ and $v$ are the dimensional velocity components along the $x$ and $y$-axes respectively, $H$ is the height, $v$ is the kinematic viscosity, $\alpha=\frac{k}{\rho C_{p}}$ is the thermal diffusivity with $k$ as the thermal conductivity, $C$ as the heat capacity, $\rho$ is the density, $\beta$ is the coefficient of the thermal expansion, $g$ is the gravity, $p$ is the pressure and $T$ is the temperature such that subscript $h$ and $c$ indicate the hot and cold respectively. The stream function is calculated from the definition $U=\frac{\partial \psi}{\partial Y}$ and $V=-\frac{\partial \psi}{\partial X}$. The local Nusselt number along the hot wall and average Nusselt number can be written as $N u_{x}=-\left(\frac{\partial \theta}{\partial Y}\right)_{Y=1}$ and $N u_{\text {avg }}=\frac{1}{A R} \int_{0}^{A R} N u_{x} d X$, respectively.

\subsection{Numerical Approach}

The dimensionless Eqs. (1) - (4), along with the corresponding boundary conditions (5), are discretized by the finite volume method $[34,35]$. The computational domain is discretized into an unstructured, cell-centered, staggered grid system by the power-law scheme on the convection and diffusion terms. The pressure and velocities components are coupled by utilizing the Semi-Implicit Method for Pressure-Linked Equations (SIMPLE) algorithm. The Tri-Diagonal Matrix Algorithm (TDMA) is used to solve the resulting discretized equations iteratively. The procedure is adapted into the FORTRAN90 programming language. When the convergence criterion is achieved, the iterative process is terminated, where $m$ and $n$ are the number of grid points in $X$ and $Y$ - directions, respectively. Here, $\eta$ is any computed variables while $r$ is the iteration number. 


$$
\frac{\sum_{j=1}^{m} \sum_{i=1}^{n}\left|\eta_{i, j}^{r+1}-\eta_{i, j}^{r}\right|}{\sum_{j=1}^{m} \sum_{i=1}^{n}\left|\eta_{i, j}^{r+1}\right|} \leq 10^{-7}
$$

To obtain a grid-independent solution, a grid sensitivity analysis is performed. Several mesh distributions ranging from 100 to 480 grid sizes for the horizontal axis were tested. Note that the grid size for the vertical axis is $\frac{1}{5}$ times the grid size on the horizontal axis. Temperature profiles along the mid-section of the horizontal cavity $(X=0.5)$ for each grid size are shown in Figure 2. It illustrates that a mesh of 400 for the horizontal axis is adequate for a grid-independent solution.

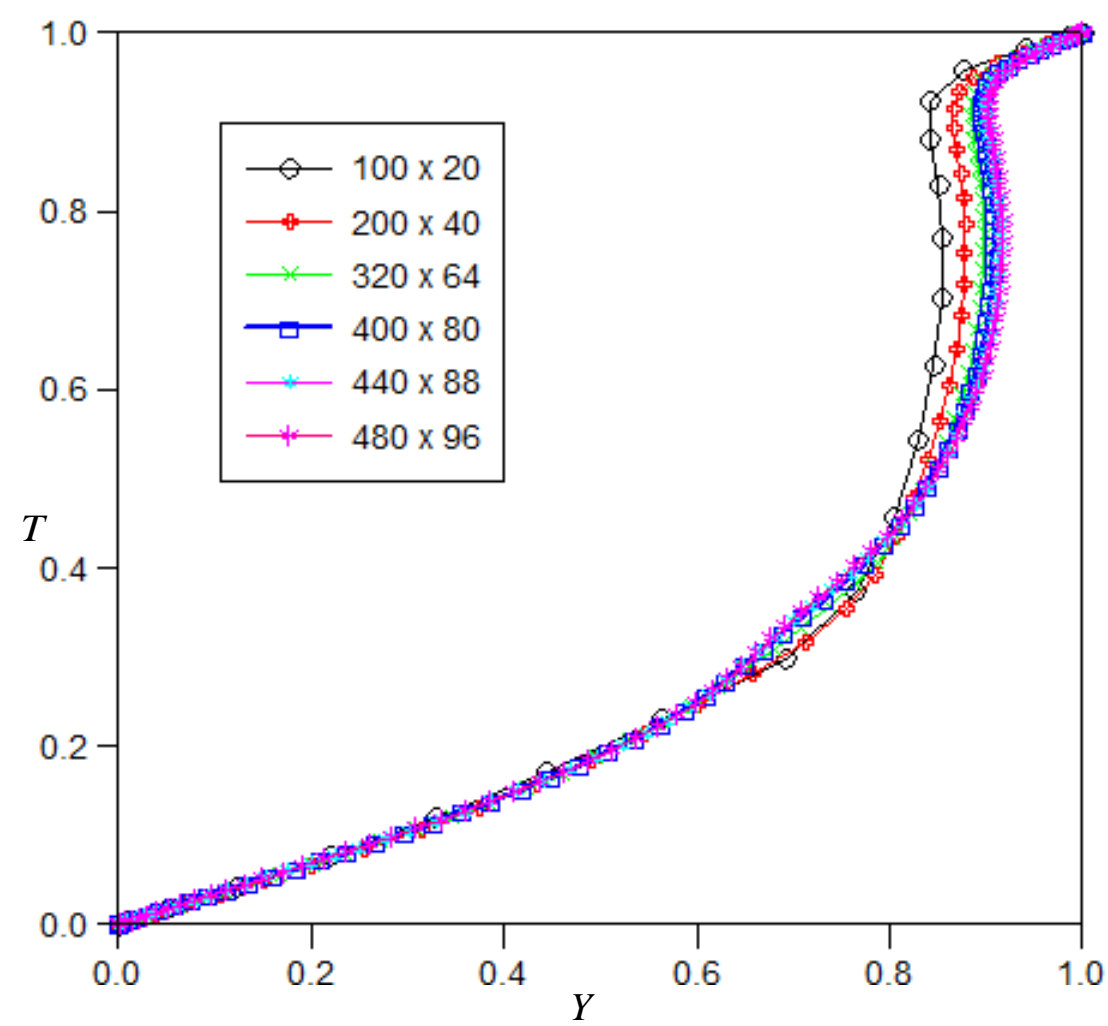

Fig. 2. Temperature profiles for different grid sizes at $X=0.5$ with $\Delta=0$ and $\mathrm{Ri}=1.0$

Three comparisons were made with previously published numerical results to verify the developed in-house computational code written in the FORTRAN90 programming language. Figure 3 shows the comparison of streamlines and isotherm trajectories with the work of Saha [30] for $\Delta=$ 3.0, $\mathrm{Pr}=0.7$, and $\mathrm{Ri}=1.0$. It is observed that the result between the present code and the existing findings is in good agreement. Furthermore, the accuracy of the current results is examined by comparing the horizontal and vertical velocities at the mid-section of the cavity with Khanafer et al., [33] and Iwatsu et al., [36]. Table 1 shows the velocities values for three numerical results. The table clearly shows that the present numerical method produces reasonably accepted results. 

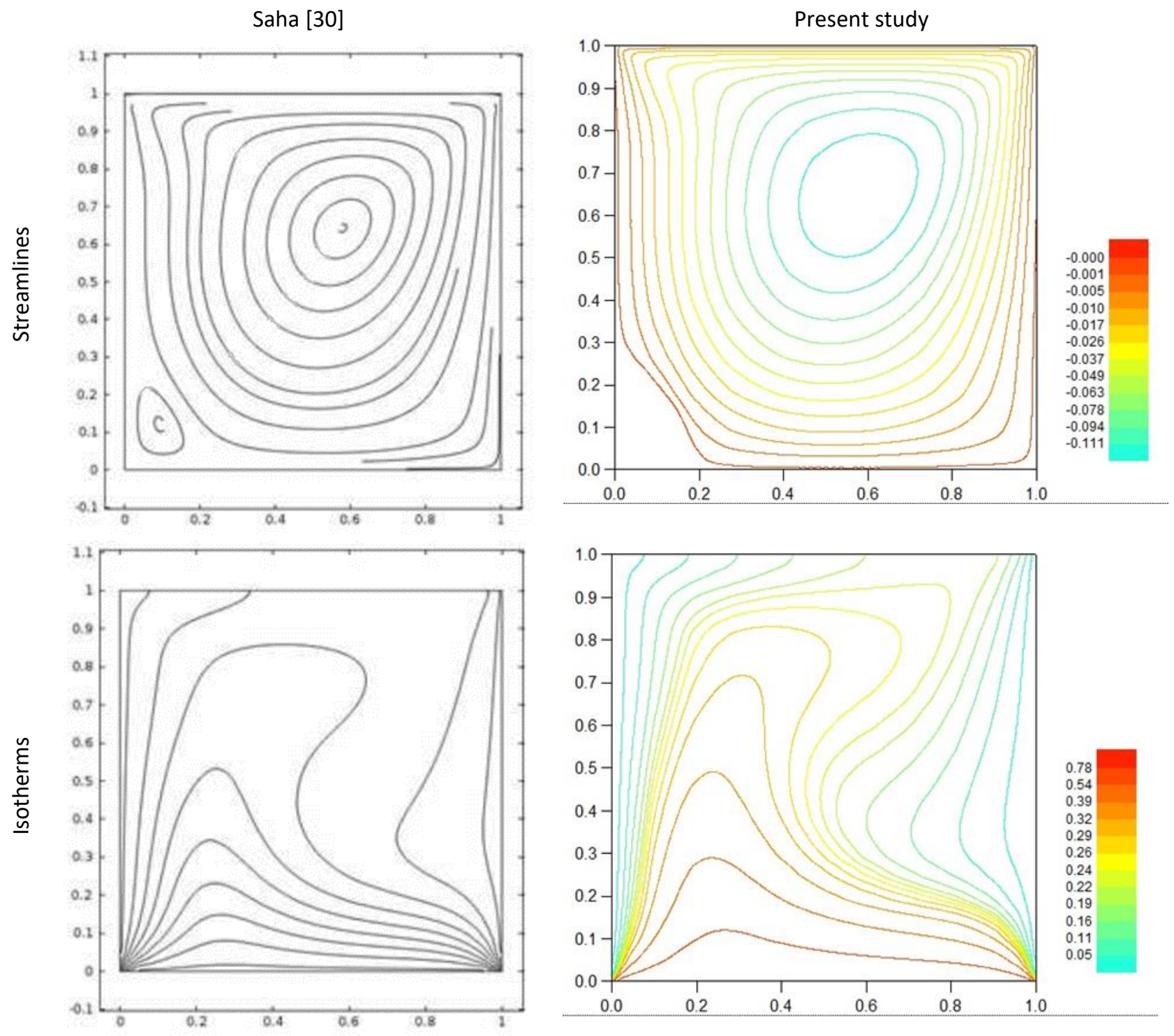

Fig. 3. Comparison of streamlines and isotherms

\section{Results}

In this study, numerical analysis on mixed convection in a rectangular lid-driven cavity has been performed to investigate the effects of internal heat generation or absorption on fluid flow and heat transfer. The upper wall moves from left to right at a constant speed $U_{x}$ and kept at a hot temperature $T_{h}$, while the bottom wall is kept at a cold temperature $T_{c}$ such that $T_{h}>T_{c}$. The vertical walls are assumed to be adiabatic. The effects of internal heat generation or absorption, ranging from -6 to 6 for $\mathrm{Ri}=1.0$ were analyzed. Water is taken as a working fluid with $\operatorname{Pr}=7.0$. The Reynold number is fixed at 408.21, following the work of Sharif [37]. The cavity aspect ratio $A R$ is taken as five. The dimensionless equations are discretized using the finite volume method and the SIMPLE algorithm. The resulting equations are then solved employing a line-by-line procedure of the tri-diagonal matrix algorithm (TDMA). The numerical results are discussed in terms of streamlines, isotherms plots, and average Nusselt numbers that measure the heat transfer rate. 


\section{Table 1}

Comparisons of the maximum and minimum values of the horizontal and vertical velocities at the mid-section of the cavity between the present solution and those reported previously $[33,36]$

\begin{tabular}{|c|c|c|c|}
\hline \multicolumn{4}{|c|}{$\operatorname{Re}=400.0$} \\
\hline & Khanafer et al., [33] & Iwatsu et al., [36] & Present \\
\hline$U_{\min }$ & -0.3099 & -0.3197 & -0.3023 \\
\hline$U_{\max }$ & 1.0000 & 1.0000 & 1.0000 \\
\hline$V_{\min }$ & -0.4363 & -0.4459 & -0.4219 \\
\hline$V_{\max }$ & 0.2866 & 0.2955 & 0.2802 \\
\hline \multicolumn{4}{|c|}{$\operatorname{Re}=100.0$} \\
\hline$U_{\min }$ & -0.2037 & -0.2122 & -0.2049 \\
\hline$U_{\max }$ & 1.0000 & 1.0000 & 1.0000 \\
\hline$V_{\min }$ & -0.2448 & -0.2506 & -0.2328 \\
\hline$V_{\max }$ & 0.1699 & 0.1765 & 0.1673 \\
\hline
\end{tabular}

Figure 4 and Figure 5 show the streamlines' variation for different values of internal heat generation or absorption for $\mathrm{Ri}=0.1$. When $\Delta=0$, the feature of the streamlines is similar to that of a conventional lid-driven rectangular cavity.

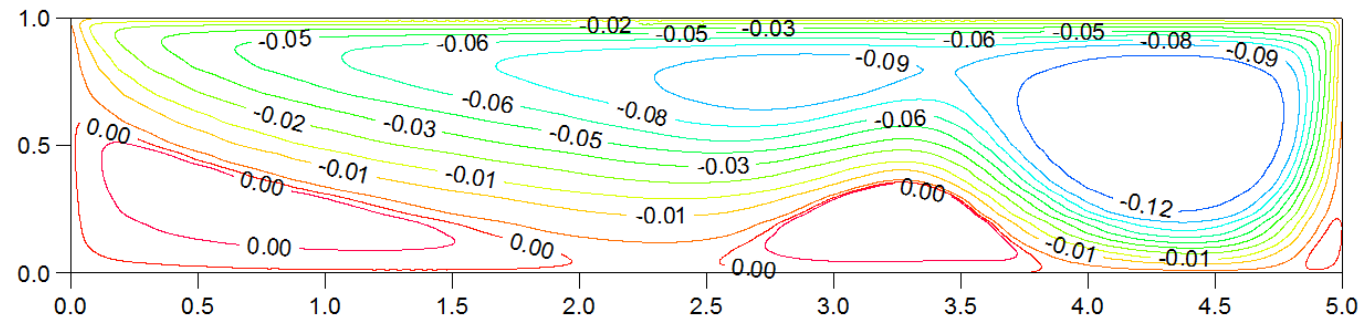

$\Delta=0$

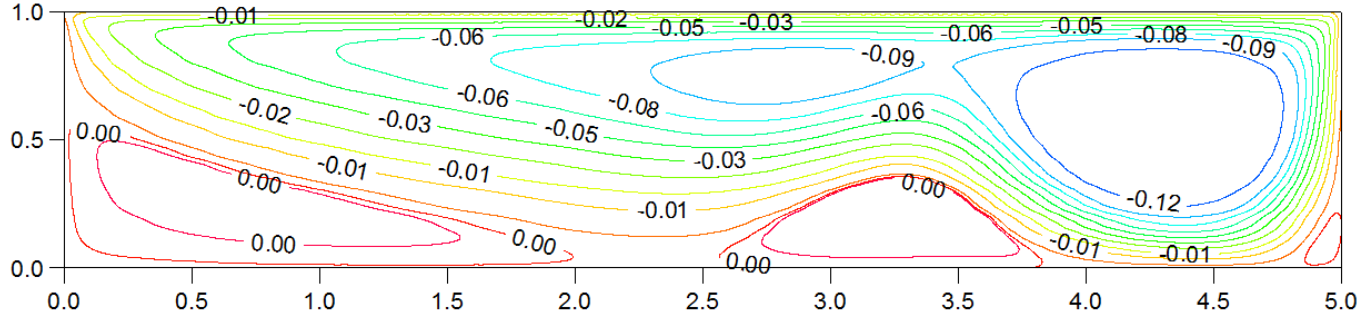

$\Delta=2$

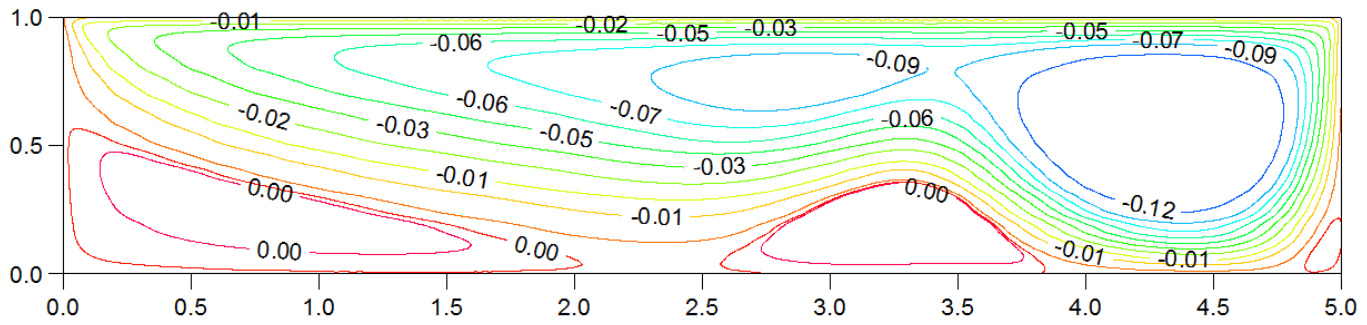

$\Delta=4$

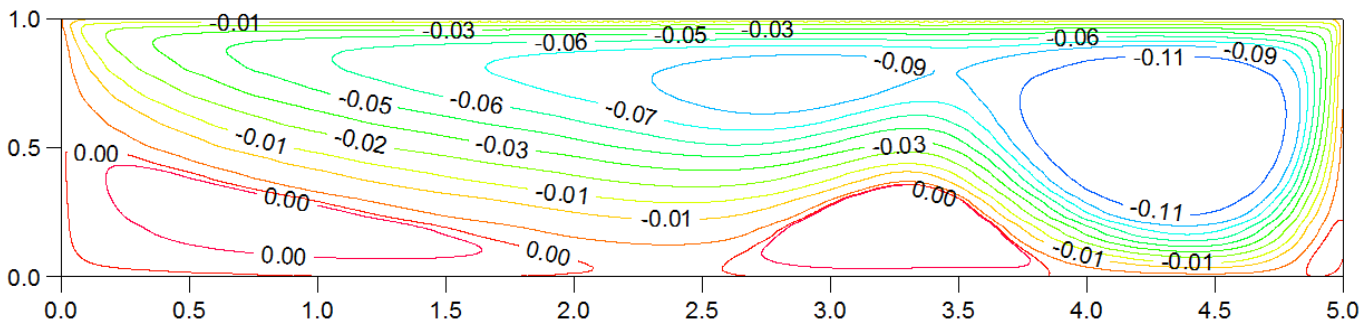

$\Delta=6$

Fig. 4. Streamlines with a different value of internal heat generation, $\Delta$ at $\mathrm{Ri}=0.1$ 


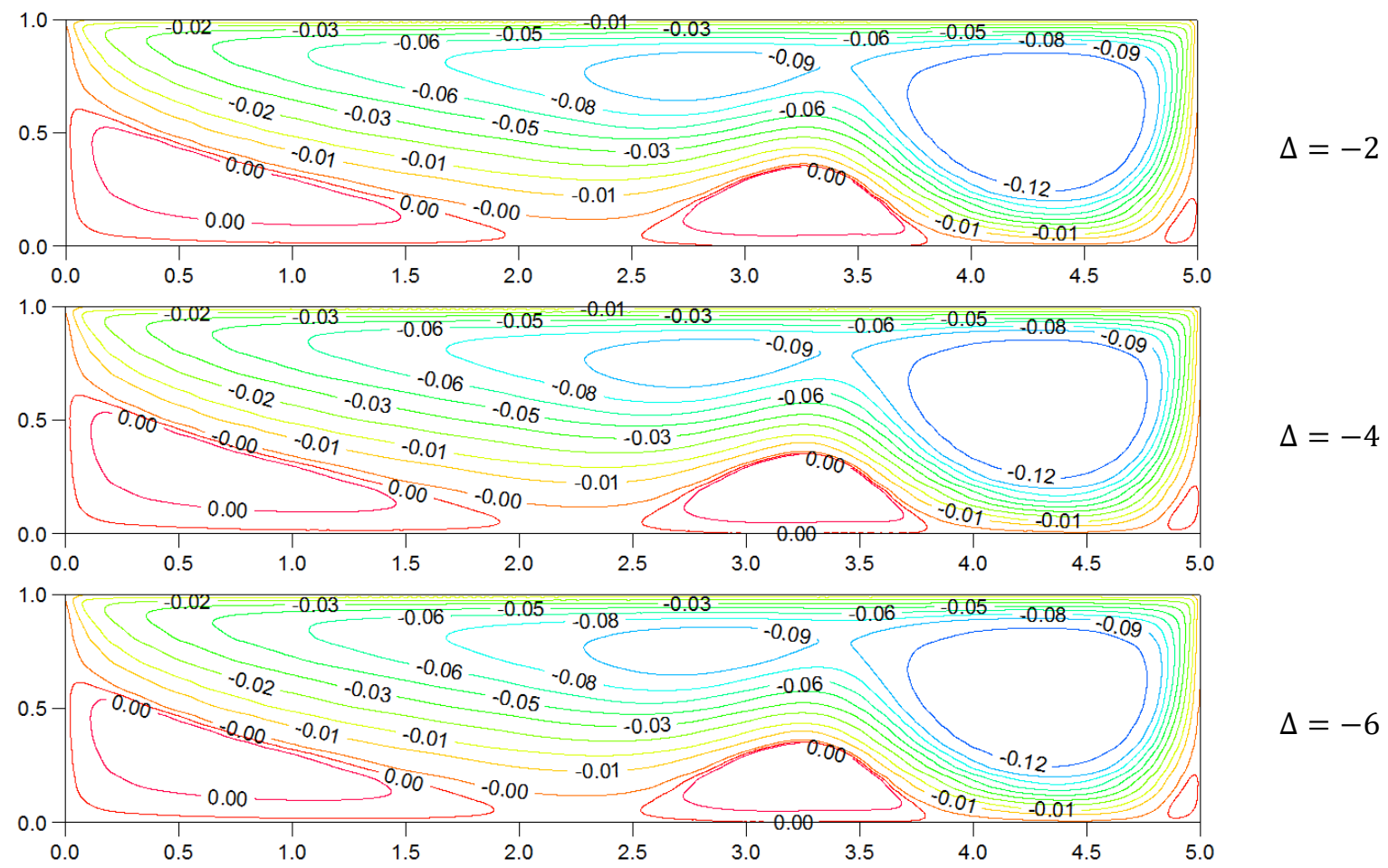

Fig. 5. Streamlines for a different value of internal heat absorption, $\Delta$ at $\mathrm{Ri}=0.1$

It is characterized by a primary recirculating clockwise cell near the cavity's right wall and two other primary recirculating anti-clockwise cells at the bottom wall. The recirculating clockwise flow is due to the impact of the shear driven flow by the lid to the right wall and is forced to move downward. The recirculation direction could be identified by the value of isolines forming the streamlines. When the value is negative, it indicates that the fluid recirculates in the clockwise direction and vice versa.

Meanwhile, for both anti-clockwise recirculating cells at the lower part of the cavity, i.e., the bottom left corner and slightly in the middle bottom of the cavity results from the buoyancy force. From these figures, it can be seen that the velocity field inside the rectangular cavity remains more or less undistinguishable for all values of $\Delta$. The internal heat generation or absorption has an insignificant impact on the flow field's development inside the cavity.

In contrast, the temperature field inside the cavity is found to experience some changes resulting from internal heat generation or absorption. This can be seen in Figures 6 and 7. In the absence of internal heat generation, the isothermal lines are clustered, and the maximum temperature occurs near the hot top wall. An increase in $\Delta$ causes the appearance of parallel lines near the hot wall, which decreases gradually and move towards the cold bottom wall. The value of isotherms also increases with the increment of $\Delta$ values. Besides, it can be viewed that the temperature gradient continuously decreases continually with an increase in the value of $\Delta$. This implies that the heating effect of the hot wall diminishes slowly as the fluid inside the cavity generates heat. The opposite effect can be seen in the case of internal heat absorption, where $\Delta<0$. The high-temperature region moves closer to the hot top wall causing higher heat transfer rates. 


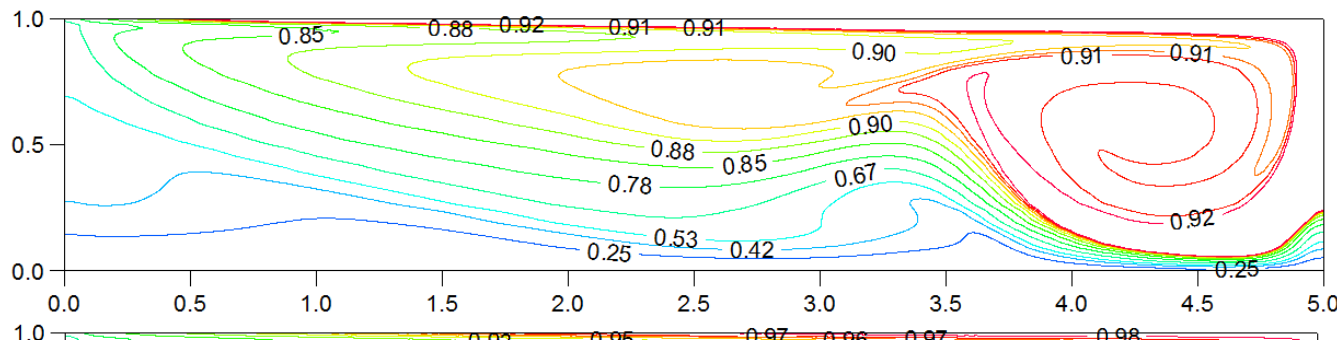

$\Delta=0$

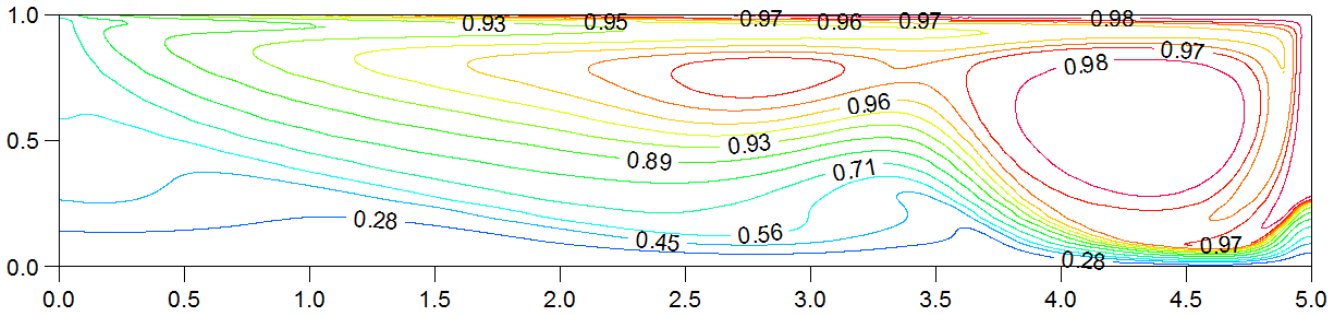

$\Delta=2$

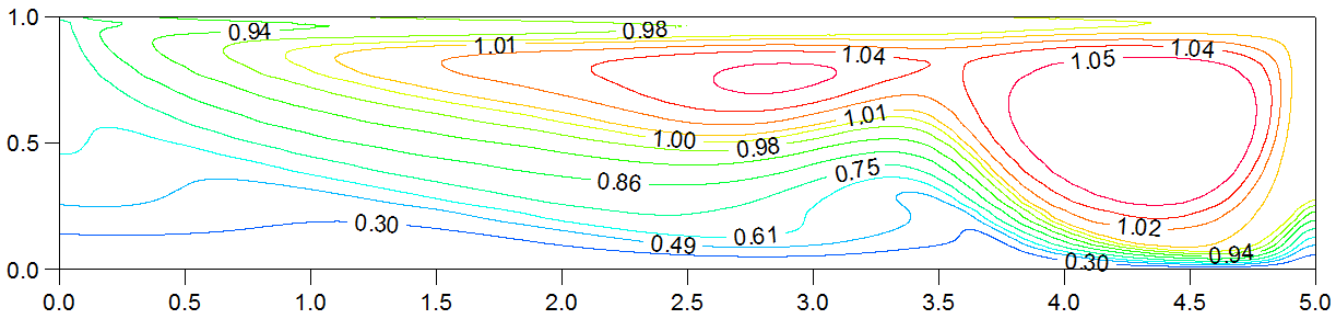

$\Delta=4$

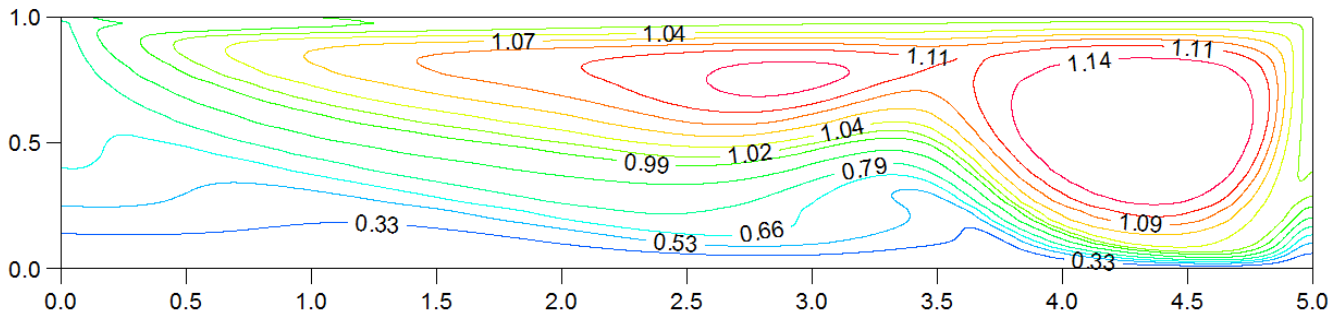

Fig. 6. Isotherms for different internal heat generation, $\Delta$ at $\mathrm{Ri}=0.1$

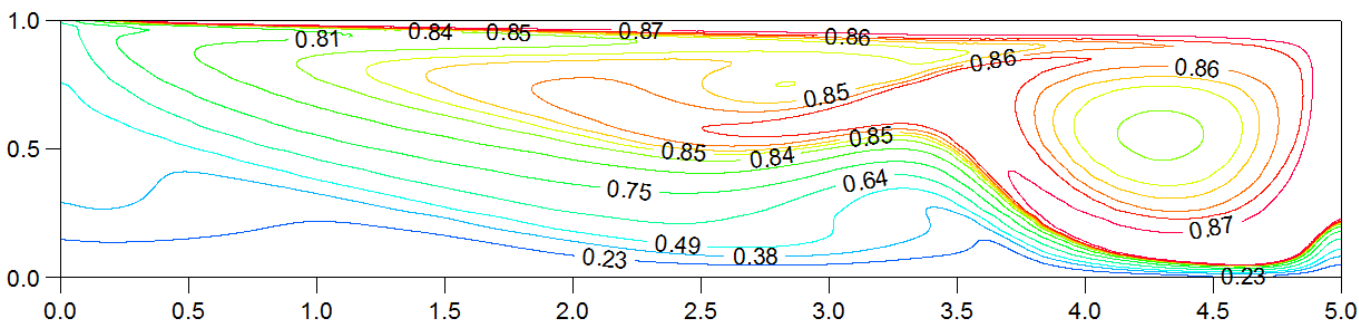

$\Delta=6$
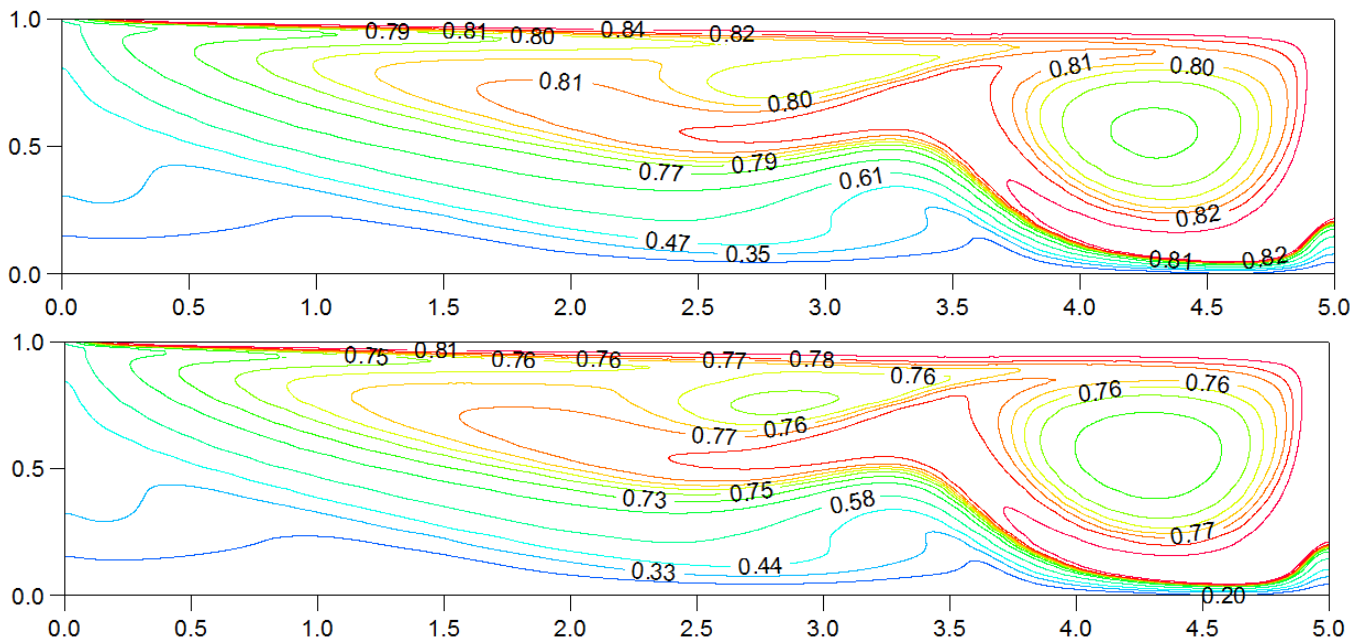

$\Delta=-4$

Fig. 7. Isotherms for different internal heat absorption, $\Delta$ at $\mathrm{Ri}=0.1$ 
The variation of streamlines for $\mathrm{Ri}=1.0$ with different internal heat generation and absorption values have the same pattern when $\mathrm{Ri}=0.1$. The streamlines variation is not shown here to avoid repetition. This strongly indicates that the flow field is not affected by the internal heat generation or absorption parameters. The isotherms for $\mathrm{Ri}=1.0$ with different values of internal heat generation or absorption are presented in Figures 8 and 9.

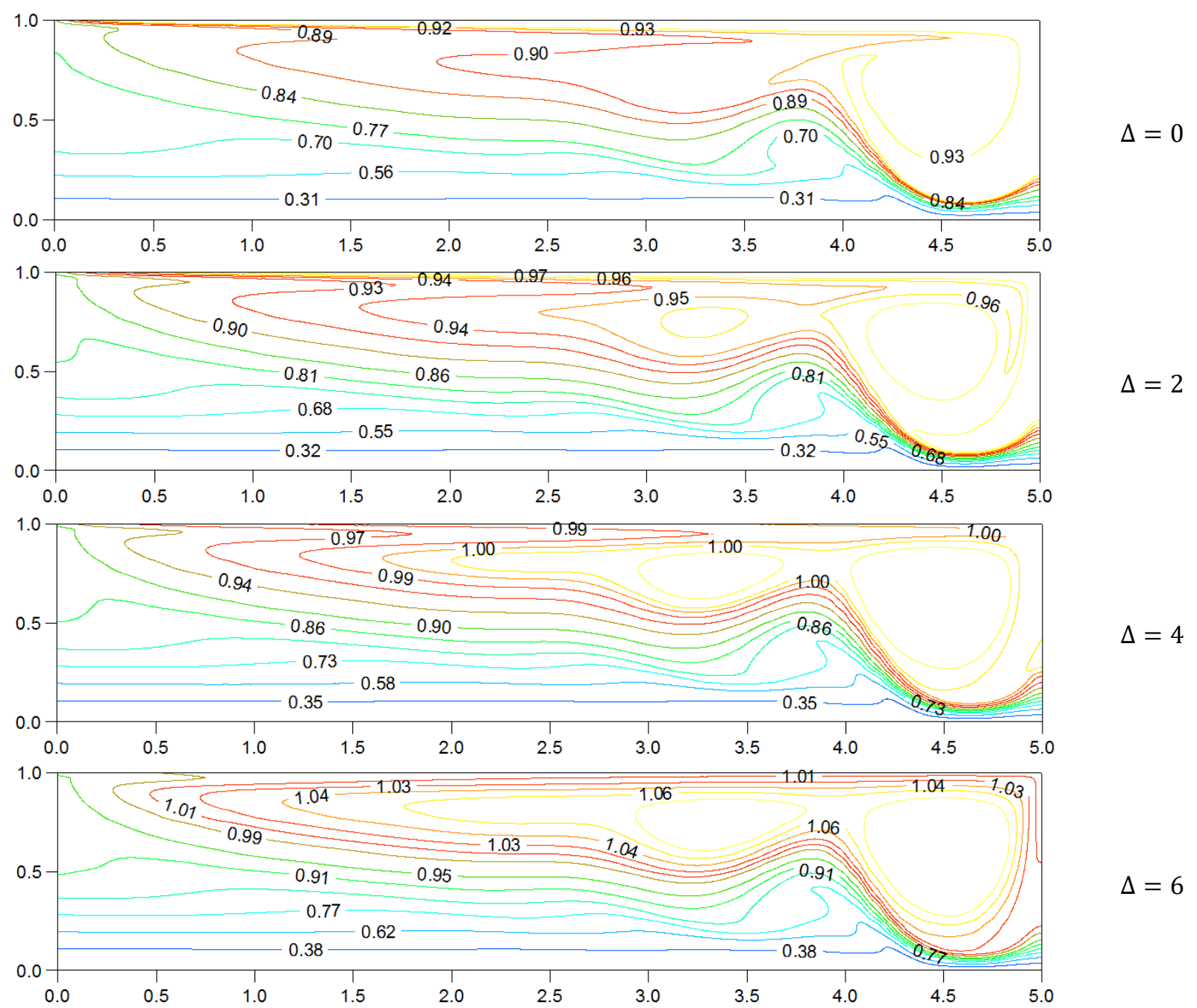

Fig. 8. Isotherms for different internal heat generation, $\Delta$ at $\mathrm{Ri}=1.0$

In contrast to the effect of internal heat generation or absorption parameter to the flow field, the isotherms react boldly to each value of $\Delta$. When the value of $\Delta$ is zero, a high-temperature gradient is detected along the top wall, especially near the right corner of the cavity. The isothermal lines are clustered near the bottom right corner of the cavity. This is due to the dominant effect of mixed convection caused by the movement of the top wall. The increment of $\Delta$ values could be seen clearly by the high values of temperature gradient in the cavity. The fluid is warmer along the bottom wall and hotter near the area of the right wall. The clustered isotherms slowly diminished as a result of heat generation increment. In Figure 9, the fluid is colder as the heat absorption value rise. This indicates a rise in the heat transfer rate even though the flow field is unaffected. 


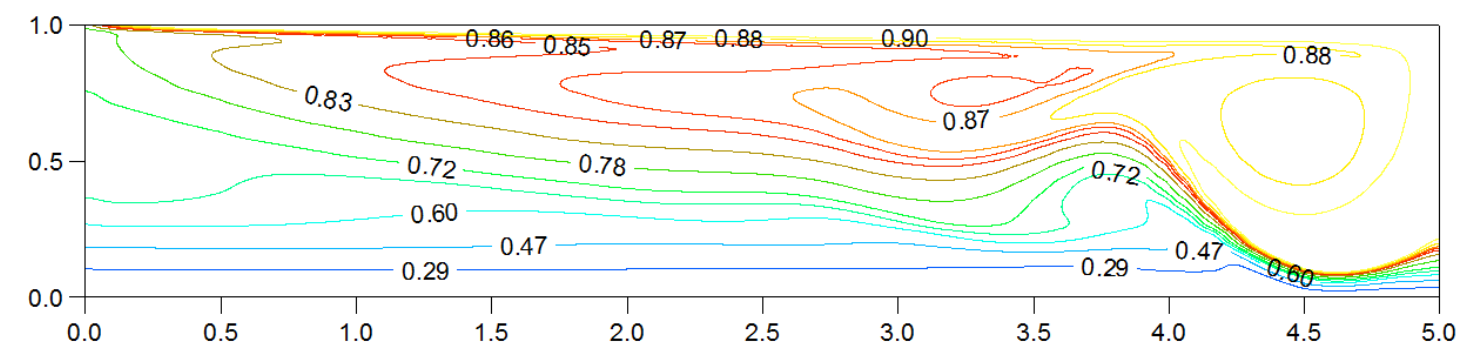

$\Delta=-2$

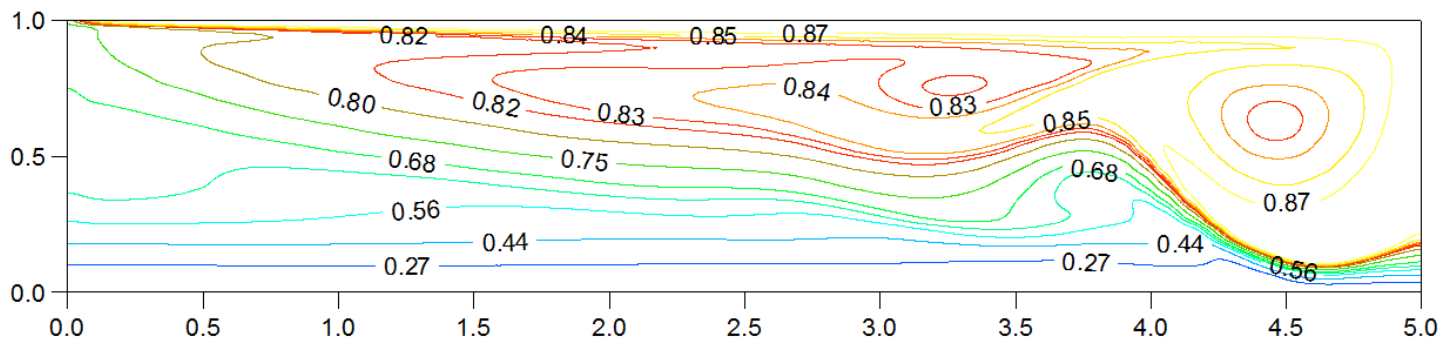

$\Delta=-4$

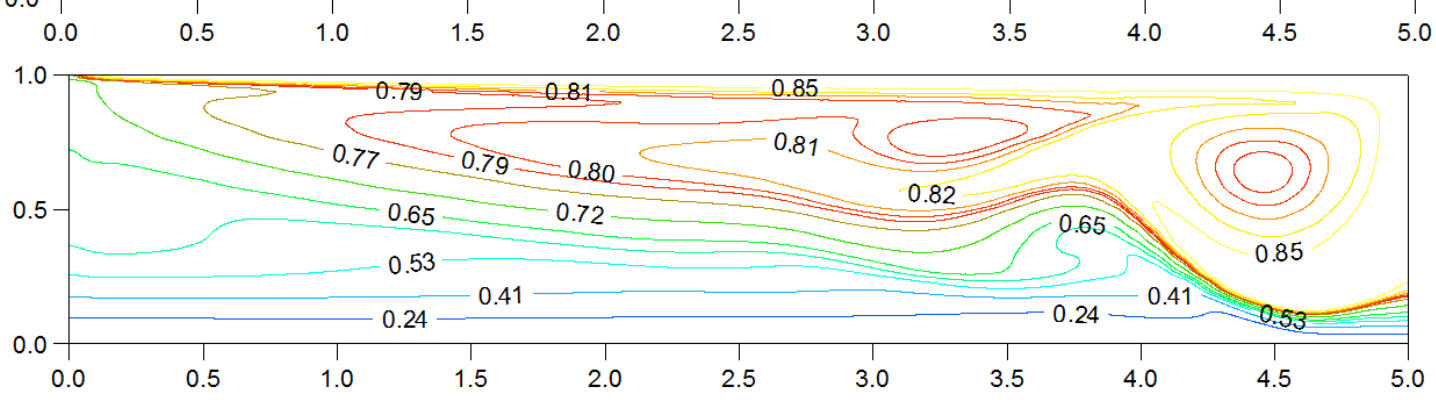

$\Delta=-6$

Fig. 9. Isotherms for different internal heat absorption, $\Delta$ at $\mathrm{Ri}=1.0$

The effect of internal heat generation or absorption value to the streamlines of natural convection dominated regime, $\mathrm{Ri}=10.0$ is presented in Figures 10 and 11 . When internal heat generation of absorption is absent, there are three primary recirculating cells in an alternate direction. The upper cavity is filled with a clockwise recirculating cell indicating the effect of top wall constant movement. At the middle of the cavity, there exists a counterclockwise recirculating cell caused by the buoyancy force. The internal heat generation significantly affects the flow field, as shown by the growing and shrinking recirculating cell at the top and bottom of the cavity, respectively. Contra to the internal heat generation effect, Figure 11 shows that streamlines patterns are quite the same for all internal heat absorption values for $\mathrm{Ri}=10.0$.

The variation of isotherms for natural convection dominated regime, $\mathrm{Ri}=10.0$ with different values of $\Delta$ is presented in Figures 12 and 13. At the cavity's right wall, clustered isothermal lines occur when the heat generation or absorption is absent. The upper right corner of the cavity is filled with a recirculating cell due to the effect of the sliding top. The other bottom half of the cavity is filled with parallel isothermal lines indicating heat transfer by conduction. As the internal heat generation increases, the upper recirculating cell grows, and the fluid is warmer. It is found that the effect of forced and natural convection has the same strength as the $\Delta$ increases. In Figure 13, the heat absorption effect on the temperature field is presented. It can be seen that heat absorption causes heat transfer by conduction at the lower half of the cavity as it rises. The recirculating cell near the right top corner slowly weakened when the heat absorption value increase. 


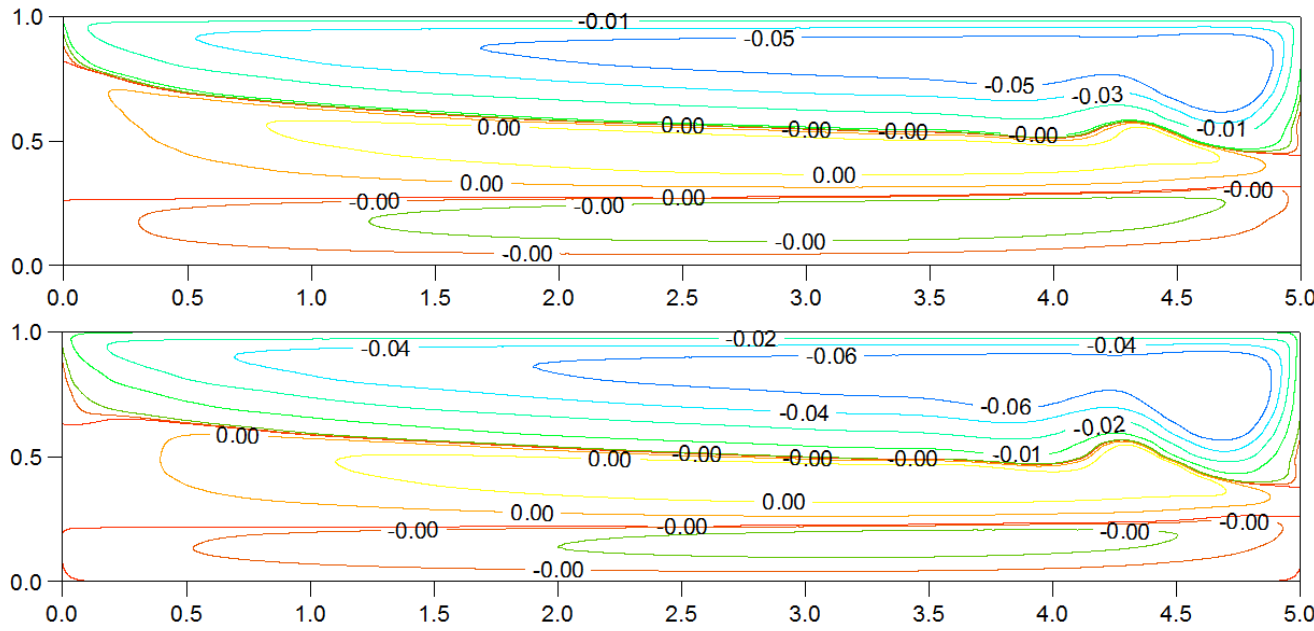

$\Delta=0$

$\Delta=2$

$\Delta=4$

$\Delta=6$
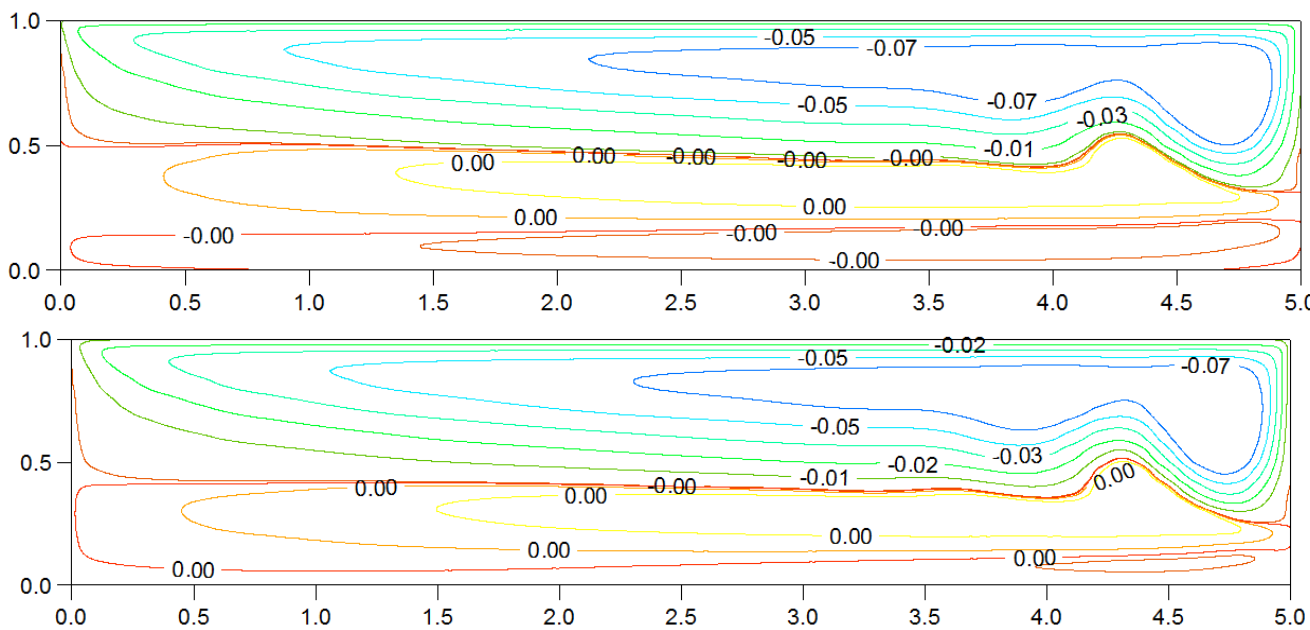

Fig. 10. Streamlines with a different value of internal heat generation, $\Delta$ at $\mathrm{Ri}=10.0$

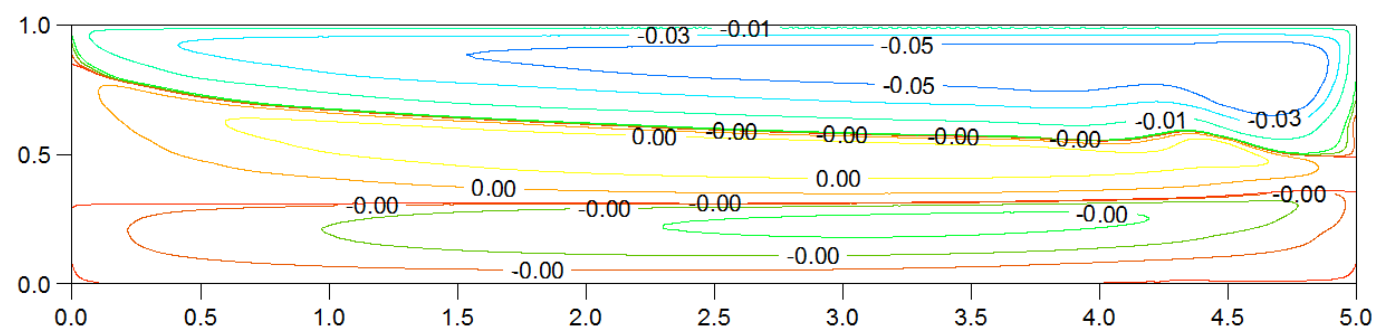

$\Delta=-2$

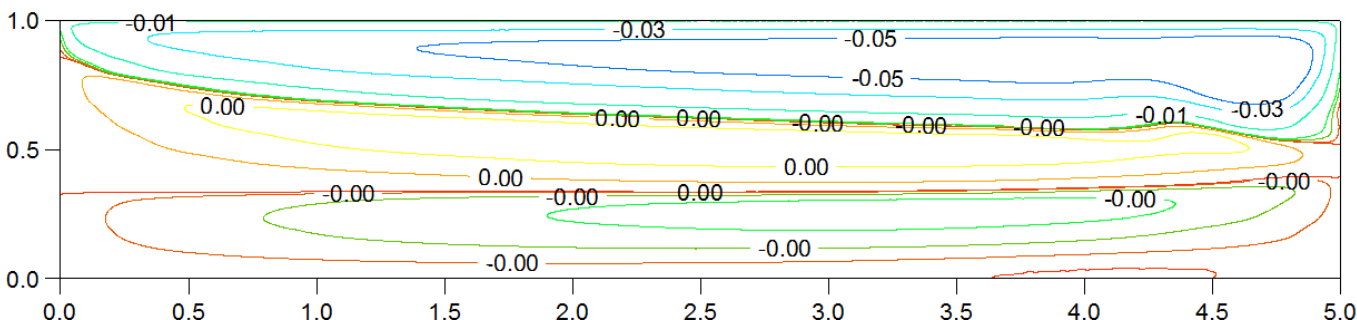

$\Delta=-4$

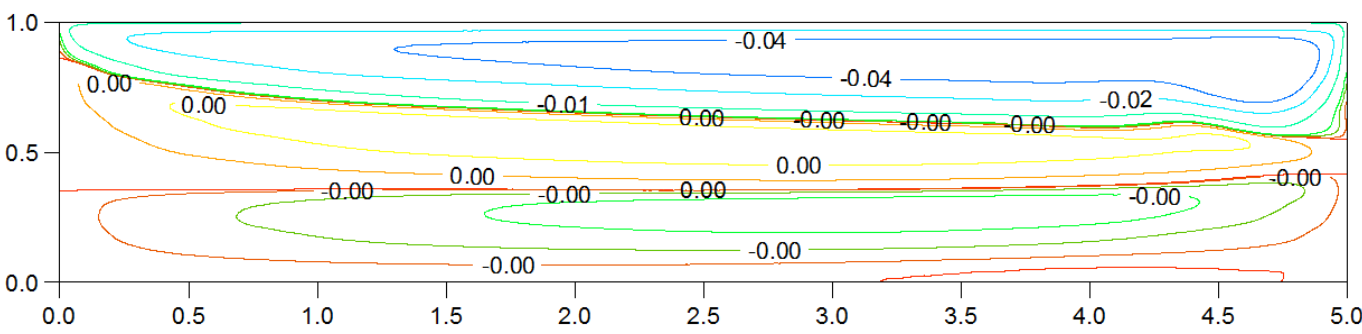

$\Delta=-6$

Fig. 11. Streamlines for different value of internal heat absorption, $\Delta$ at $\mathrm{Ri}=10.0$ 


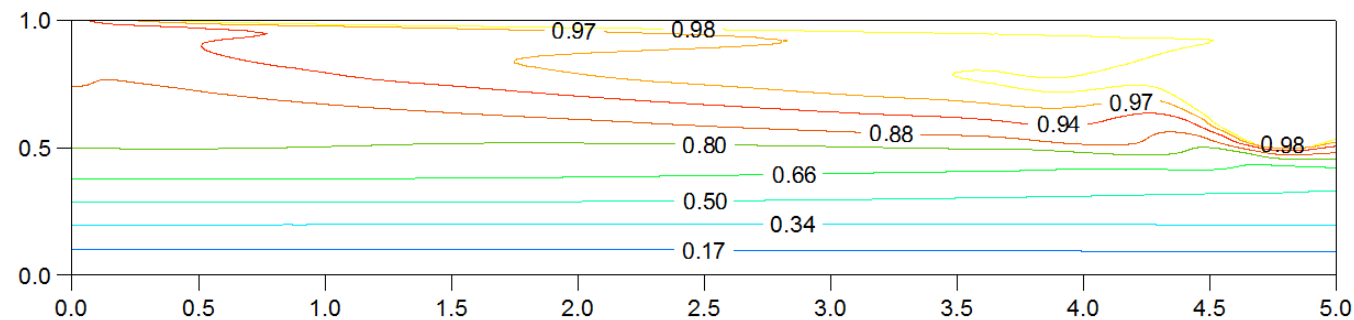

$\Delta=0$

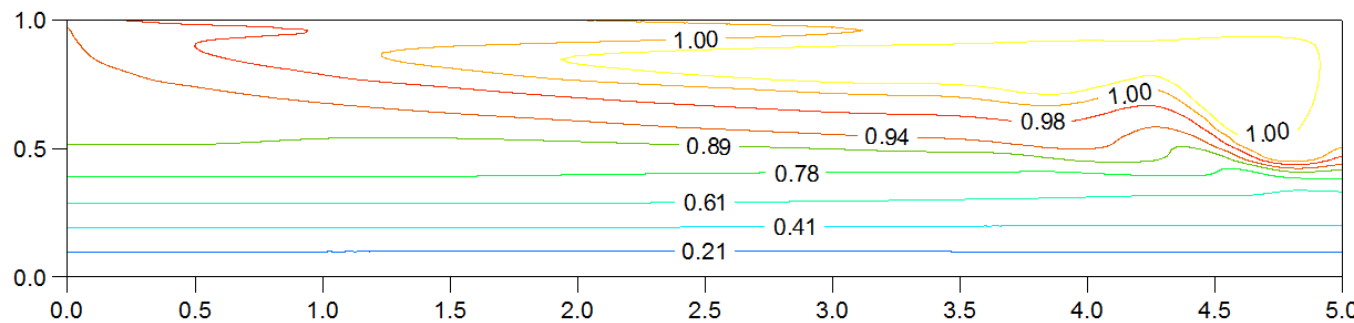

$\Delta=2$

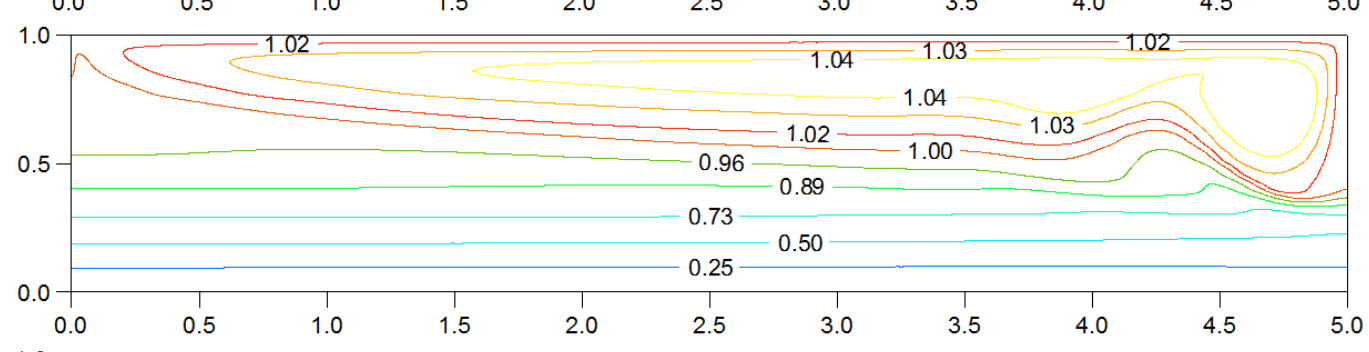

$\Delta=4$

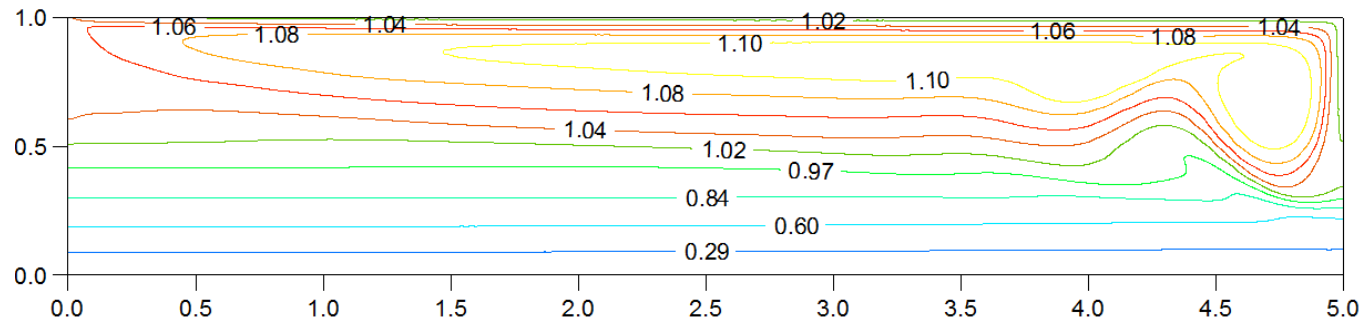

Fig. 12. Isotherms for different internal heat generation, $\Delta$ at $\mathrm{Ri}=10.0$
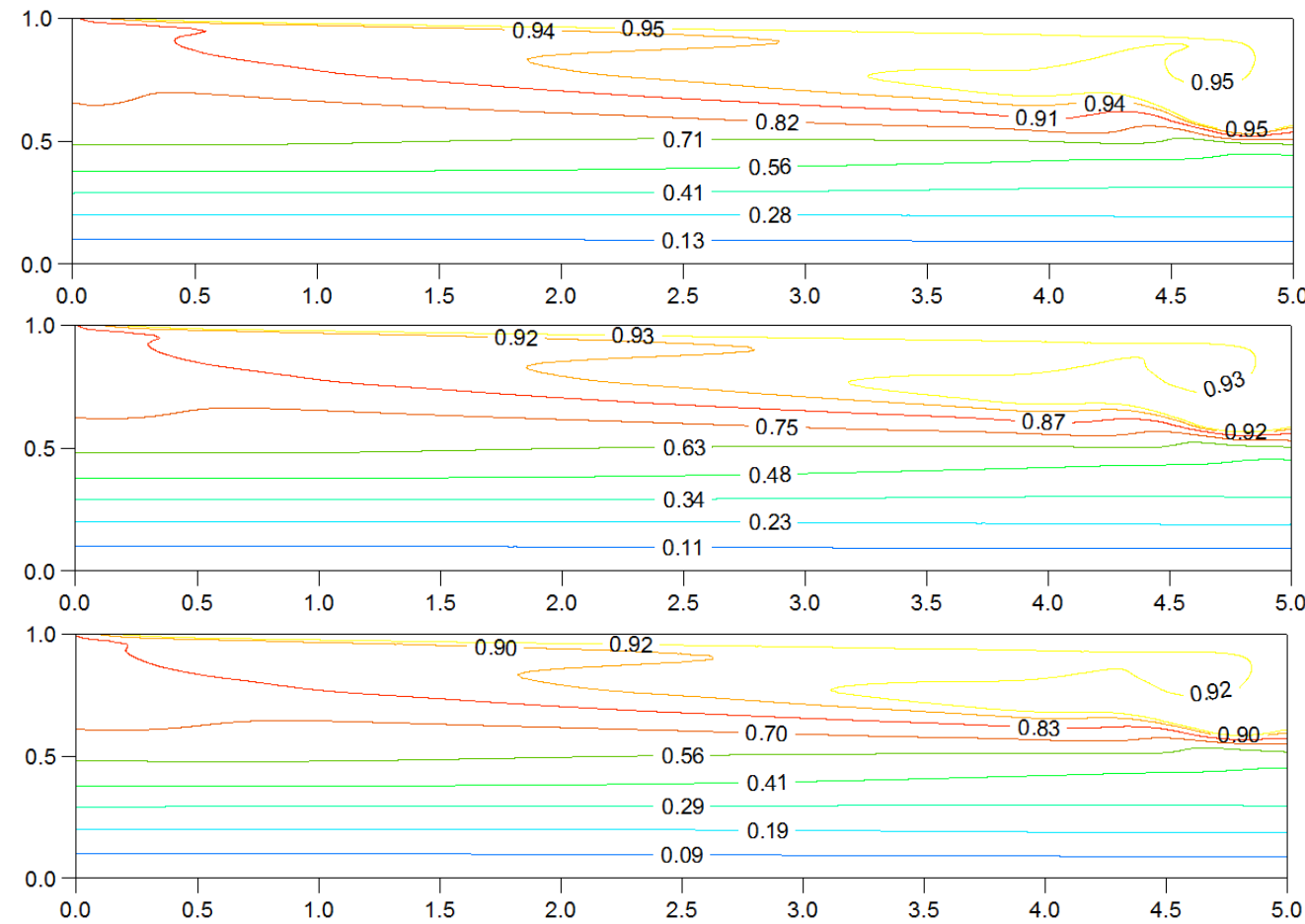

$\Delta=6$

$\Delta=-2$

$\Delta=-4$

$\Delta=-6$

Fig. 13. Isotherms for different internal heat absorption, $\Delta$ at $\mathrm{Ri}=10.0$ 
The variations of the average Nusselt number is depicted in Figure 14. Overall, for internal heat generation, the heat transfer decreases while the opposite pattern can be observed for the case of internal heat absorption. However, for $\mathrm{Ri}=10.0$, as the heat generation's value increases from 2 to 4 , the heat transfer rate remains the same. Then, the average Nusselt number increases back for the same case. This shows that for natural convection dominated regime, the value of heat generation plays a significant role.

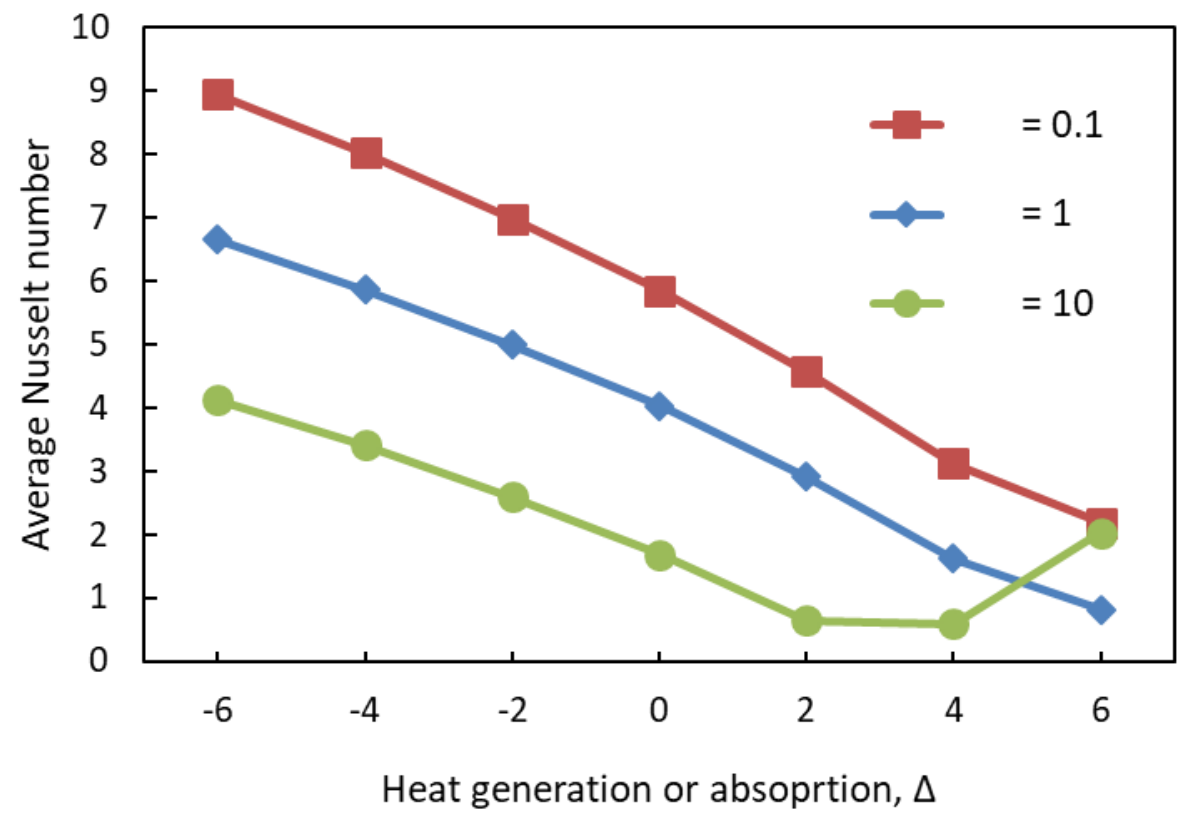

Fig. 14. Average Nusselt number for internal heat generation or absorption value

\section{Conclusions}

A numerical study has been carried out to examine the internal heat generation or absorption on mixed convection in a rectangular lid-driven cavity. The top wall is moved at a constant speed in its plane and kept at a hot temperature, while the bottom wall is not moved and kept at a cold temperature. Note that the vertical walls are adiabatic. The Pr and Re values are fixed at 7.0 and 408.21, respectively. The obtained results are presented in terms of streamlines and isotherms plots as well as average Nusselt number. The results of the numerical analysis show that the heat transfer increases in the case of internal heat absorption and vice versa for the case of internal heat generation.

\section{Acknowledgement}

This research is funded by a grant from Universiti Tun Hussein Onn Malaysia Grant No. TIER 1/H184.

\section{References}

[1] Elbashbeshy, Elsayed MA, T. G. Emam, and K. M. Abdelgaber. "Effects of thermal radiation and magnetic field on unsteady mixed convection flow and heat transfer over an exponentially stretching surface with suction in the presence of internal heat generation/absorption." Journal of the Egyptian Mathematical Society 20, no. 3 (2012): 215-222. https://doi.org/10.1016/i.joems.2012.08.016

[2] Mansour, M. A., Ali J. Chamkha, R. A. Mohamed, M. M. Abd El-Aziz, and S. E. Ahmed. "MHD natural convection in an inclined cavity filled with a fluid saturated porous medium with heat source in the solid phase." Nonlinear Analysis: Modelling and Control 15, no. 1 (2010): 55-70. 
https://doi.org/10.15388/NA.2010.15.1.14364

[3] Chamkha, Ali J., Salam Hadi Hussain, Farooq Hassan Ali, and Ahmed Ali Shaker. "Conduction-combined forced and natural convection in a lid-driven parallelogram-shaped enclosure divided by a solid partition." Progress in Computational Fluid Dynamics, an International Journal 12, no. 5 (2012): 309-321. https://doi.org/10.1504/PCFD.2012.049101

[4] Aghaei, Alireza, Hossein Khorasanizadeh, Ghanbarali Sheikhzadeh, and Mahmoud Abbaszadeh. "Numerical study of magnetic field on mixed convection and entropy generation of nanofluid in a trapezoidal enclosure." Journal of Magnetism and Magnetic Materials 403 (2016): 133-145.

https://doi.org/10.1016/i.jmmm.2015.11.067

[5] Chamkha, A. J., A. M. Rashad, M. A. Mansour, T. Armaghani, and M. Ghalambaz. "Effects of heat sink and source and entropy generation on MHD mixed convection of a Cu-water nanofluid in a lid-driven square porous enclosure with partial slip." Physics of Fluids 29, no. 5 (2017): 052001. https://doi.org/10.1063/1.4981911

[6] Hussain, Shafqat, Sameh E. Ahmed, and Farrukh Saleem. "Impact of periodic magnetic field on entropy generation and mixed convection." Journal of Thermophysics and Heat Transfer 32, no. 4 (2018): 999-1012.

https://doi.org/10.2514/1.T5430

[7] Abu-Nada, Eiyad, and Ali J. Chamkha. "Mixed convection flow of a nanofluid in a lid-driven cavity with a wavy wall." International Communications in Heat and Mass Transfer 57 (2014): 36-47.

https://doi.org/10.1016/i.icheatmasstransfer.2014.07.013

[8] Cho, Ching-Chang. "Mixed convection heat transfer and entropy generation of Cu-water nanofluid in wavy-wall liddriven cavity in presence of inclined magnetic field." International Journal of Mechanical Sciences 151 (2019): $703-$ 714.

https://doi.org/10.1016/i.ijmecsci.2018.12.017

[9] Anandalakshmi, R., and Tanmay Basak. "Heat flow visualization analysis on natural convection in rhombic enclosures with isothermal hot side or bottom wall." European Journal of Mechanics-B/Fluids 41 (2013): 29-45. https://doi.org/10.1016/i.euromechflu.2013.03.006

[10] Kakaç, Sadık, and Anchasa Pramuanjaroenkij. "Single-phase and two-phase treatments of convective heat transfer enhancement with nanofluids-A state-of-the-art review." International journal of thermal sciences 100 (2016): 7597.

https://doi.org/10.1016/j.ijthermalsci.2015.09.021

[11] Chamkha, Ali J., and Muneer A. Ismael. "Magnetic field effect on mixed convection in lid-driven trapezoidal cavities filled with a $\mathrm{Cu}$-water nanofluid with an aiding or opposing side wall." Journal of Thermal Science and Engineering Applications 8, no. 3 (2016). https://doi.org/10.1115/1.4033211

[12] Javed, Tariq, Z. Mehmood, and Z. Abbas. "Natural convection in square cavity filled with ferrofluid saturated porous medium in the presence of uniform magnetic field." Physica B: Condensed Matter 506 (2017): 122-132. https://doi.org/10.1016/j.physb.2016.11.008

[13] Selimefendigil, Fatih, and Ali J. Chamkha. "Magnetohydrodynamics mixed convection in a lid-driven cavity having a corrugated bottom wall and filled with a non-Newtonian power-law fluid under the influence of an inclined magnetic field." Journal of Thermal Science and Engineering Applications 8, no. 2 (2016). https://doi.org/10.1115/1.4032760

[14] Kalteh, Mohammad, Kourosh Javaherdeh, and Toraj Azarbarzin. "Numerical solution of nanofluid mixed convection heat transfer in a lid-driven square cavity with a triangular heat source." Powder Technology 253 (2014): $780-788$. https://doi.org/10.1016/i.powtec.2013.12.039

[15] Ghouizi, Jamal, Mohamed Nabou, Mohammed Elmir, Mohamed Douha, and Mehdi Berramdane. "Numerical Simulation of Natural Convection in A Cavity Filled with A Nanofluid Who's Wall Containing the Heat Source Is Inclined." Journal of Advanced Research in Fluid Mechanics and Thermal Sciences 76, no. 1 (2020): 1-16. https://doi.org/10.37934/arfmts.76.1.116

[16] Chamkha, Ali J. "Double-diffusive convection in a porous enclosure with cooperating temperature and concentration gradients and heat generation or absorption effects." Numerical Heat Transfer: Part A: Applications 41, no. 1 (2002): 65-87. https://doi.org/10.1080/104077802317221447

[17] Javed, Tariq, and Muhammad Arshad Siddiqui. "Effect of MHD on heat transfer through ferrofluid inside a square cavity containing obstacle/heat source." International Journal of Thermal Sciences 125 (2018): 419-427. https://doi.org/10.1016/j.ijthermalsci.2017.12.009 
[18] Chamkha, Ali J., and Muneer A. Ismael. "Magnetic field effect on mixed convection in lid-driven trapezoidal cavities filled with a $\mathrm{Cu}$-water nanofluid with an aiding or opposing side wall." Journal of Thermal Science and Engineering Applications 8, no. 3 (2016). https://doi.org/10.1115/1.4033211

[19] Khan, Ansab Azam, Suliadi Firdaus Sufahani, Khairy Zaimi, and Mohammad Ferdows. "MHD Flow and Heat Transfer of Double Stratified Micropolar Fluid over a Vertical Permeable Shrinking/Stretching Sheet with Chemical Reaction and Heat Source." Journal of Advanced Research in Applied Sciences and Engineering Technology 21, no. 1 (2020): 1-14. https://doi.org/10.37934/araset.21.1.114

[20] Garmroodi, MR Daneshvar, A. Ahmadpour, and F. Talati. "MHD mixed convection of nanofluids in the presence of multiple rotating cylinders in different configurations: A two-phase numerical study." International Journal of Mechanical Sciences 150 (2019): 247-264.

https://doi.org/10.1016/i.ijmecsci.2018.10.037

[21] Jamil, Dzuliana Fatin, Salah Uddin, and Rozaini Roslan. "The Effects of Magnetic Casson Blood Flow in an Inclined Multi-stenosed Artery by using Caputo-Fabrizio Fractional Derivatives." Journal of Advanced Research in Materials Science 72, no. 1 (2020): 15-30. https://doi.org/10.37934/arms.72.1.1530

[22] Eldabe, Nabil Tawfik, Mohamed Abouzeid, and Hamida A. Shawky. "MHD Peristaltic Transport of Bingham Blood Fluid with Heat and Mass Transfer Through a Non-Uniform Channel." Journal of Advanced Research in Fluid Mechanics and Thermal Sciences 77, no. 2 (2021): 145-159.

https://doi.org/10.37934/arfmts.77.2.145159

[23] Yusof, Nur Syamila, Siti Khuzaimah Soid, Mohd Rijal Illias, Ahmad Sukri Abd Aziz, and Nor Ain Azeany Mohd Nasir. "Radiative Boundary Layer Flow of Casson Fluid Over an Exponentially Permeable Slippery Riga Plate with Viscous Dissipation." Journal of Advanced Research in Applied Sciences and Engineering Technology 21, no. 1 (2020): 41-51.

https://doi.org/10.37934/araset.21.1.4151

[24] Begum, A. Shamadhani, N. Nithyadevi, Hakan F. Öztop, and Khaled Al-Salem. "Numerical simulation of MHD mixed convection in a nanofluid filled non-darcy porous enclosure." International Journal of Mechanical Sciences 130 (2017): 154-166. https://doi.org/10.1016/j.ijmecsci.2017.06.008

[25] Mehmood, Ziafat. "Numerical simulations and linear stability analysis of mixed thermomagnetic convection through two lid-driven entrapped trapezoidal cavities enclosing ferrofluid saturated porous medium." International Communications in Heat and Mass Transfer 109 (2019): 104345. https://doi.org/10.1016/i.icheatmasstransfer.2019.104345

[26] Muthtamilselvan, M., and Deog Hee Doh. "Mixed convection of heat generating nanofluid in a lid-driven cavity with uniform and non-uniform heating of bottom wall." Applied Mathematical Modelling 38, no. 13 (2014): 3164-3174. https://doi.org/10.1016/i.apm.2013.11.033

[27] Sivasankaran, S., V. Sivakumar, Ahmed Kadhim Hussein, and P. Prakash. "Mixed convection in a lid-driven twodimensional square cavity with corner heating and internal heat generation." Numerical Heat Transfer, Part A: Applications 65, no. 3 (2014): 269-286. https://doi.org/10.1080/10407782.2013.826017

[28] Rajarathinam, M., and N. Nithyadevi. "Heat transfer enhancement of Cu-water nanofluid in an inclined porous cavity with internal heat generation." Thermal Science and Engineering Progress 4 (2017): 35-44. https://doi.org/10.1016/i.tsep.2017.08.003

[29] Hussain, Shafqat, Hakan F. Öztop, Khalid Mehmood, and Nidal Abu-Hamdeh. "Effects of inclined magnetic field on mixed convection in a nanofluid filled double lid-driven cavity with volumetric heat generation or absorption using finite element method." Chinese journal of physics 56, no. 2 (2018): 484-501.

https://doi.org/10.1016/i.cjph.2018.02.002

[30] Sumon Saha, Mohammad Nasim Hasan, Goutam Saha and Md Islam Quamrul. 2010. "Effect of inclination angle on mixed convection in a lid-driven square enclosure with internal heat generation or absorption". Proceedings of International Conference on Mechanical, Industrial and Energy Engineering 2010:1-6.

[31] Chamkha, Ali J. "Hydromagnetic combined convection flow in a vertical lid-driven cavity with internal heat generation or absorption." Numerical Heat Transfer: Part A: Applications 41, no. 5 (2002): 529-546. https://doi.org/10.1080/104077802753570356 
[32] Rehena Nasrin, Alim, M.A. and Ali, J. Chamkha. 2014. "Modeling of mixed convective heat transfer utilizing nanofluid in a double lid-driven chamber with internal heat generation". International Journal of Numerical Methods for Heat and Fluid Flow 24,no. 1 (2014): 36-57.

https://doi.org/10.1108/HFF-11-2011-0239

[33] Khanafer, Khalil M., and Ali J. Chamkha. "Mixed convection flow in a lid-driven enclosure filled with a fluid-saturated porous medium." International Journal of Heat and Mass Transfer 42, no. 13 (1999): 2465-2481. https://doi.org/10.1016/S0017-9310(98)00227-0

[34] Patankar, Suhas V. "Numerical heat transfer and fluid flow(Book)." Washington, DC, Hemisphere Publishing Corp., 1980. $210 p$ (1980).

[35] Saha, Litan Kumar, KM Salah Uddin, and M. A. Taher. "Effect of internal heat generation or absorption on MHD mixed convection flow in a lid driven cavity." American Journal of Applied Mathematics 3, no. 1-1 (2015): 20-29. https://doi.org/10.11648/i.ajam.s.2015030101.13

[36] Iwatsu, Reima, Jae Min Hyun, and Kunio Kuwahara. "Mixed convection in a driven cavity with a stable vertical temperature gradient." International Journal of Heat and Mass Transfer 36, no. 6 (1993): 1601-1608. https://doi.org/10.1016/S0017-9310(05)80069-9

[37] Sharif, M. A. R. "Laminar mixed convection in shallow inclined driven cavities with hot moving lid on top and cooled from bottom." Applied thermal engineering 27, no. 5-6 (2007): 1036-1042.

https://doi.org/10.1016/i.applthermaleng.2006.07.035 